\title{
Adoption of immunotherapy in the community for patients diagnosed with metastatic melanoma
}

\author{
Marieke J. Krimphove ${ }^{1,2}$, Karl H. Tully ${ }^{3}$, David F. Friedlander ${ }^{1}$, Maya Marchese' ${ }^{1}$, Praful Ravi', Stuart R. Lipsitz ${ }^{4}$, \\ Kerry L. Kilbridge ${ }^{5}$, Adam S. Kibel ${ }^{1}$, Luis A. Kluth², Patrick A. Ott ${ }^{5}$, Toni K. Choueiri ${ }^{5}$ and Quoc-Dien Trinh ${ }^{1 *}$ (i)
}

\begin{abstract}
Background: The introduction of immune checkpoint inhibitors has led to a survival benefit in patients with advanced melanoma; however data on the adoption of immunotherapy in the community are scarce.

Methods: Using the National Cancer Database, we identified 4725 patients aged $\geq 20$ diagnosed with metastatic melanoma in the United States between 2011 and 2015. Multinomial regression was used to identify factors associated with the receipt of treatment at a low vs. high immunotherapy prescribing hospital, defined as the bottom and top quintile of hospitals according to their proportion of treating metastatic melanoma patients with immunotherapy.

Results: We identified 246 unique hospitals treating patients with metastatic melanoma. Between 2011 and 2015, the proportion of hospitals treating at least $20 \%$ of melanoma patients with immunotherapy within 90 days of diagnosis increased from 14.5 to $37.7 \%$. The mean proportion of patients receiving immunotherapy was $7.8 \%$ (95\% Confidence Interval [CI 7.47-8.08) and 50.9\% (95\%-Cl 47.6-54.3) in low and high prescribing hospitals, respectively. Predictors of receiving care in a low prescribing hospital included underinsurance (no insurance: relative risk ratio [RRR] 2.44, 95\%-Cl 1.28-4.67, $p=0.007$; Medicaid: RRR 2.10,95\%-Cl 1.12-3.92, $p=0.020$ ), care in urban areas (RRR $2.58,95 \%-\mathrm{Cl} 1.34-4.96, p=0.005$ ) and care at non-academic facilities (RRR 5.18, 95\%Cl 1.69-15.88, $p=0.004$ ).

Conclusion: While the use of immunotherapy for metastatic melanoma has increased over time, adoption varies widely across hospitals. Underinsured patients were more likely to receive treatment at low immunotherapy prescribing hospitals. The variation suggests inequity in access to these potentially life-saving drugs.
\end{abstract}

Keywords: Metastatic melanoma, Immunotherapy, Checkpoint inhibitors, Health services research, Ipilimumab

\section{Introduction}

The incidence of melanoma is rising, with the majority of cases diagnosed at localized stages, with relatively high cure rates [1]. However, recurrent and metastatic melanoma is associated with a worse prognosis. The emergence of immune checkpoint inhibitors have ushered in a new era of therapy for recurrent and advanced melanoma and many other [2-4]. In early 2011, the Food and Drug Administration (FDA) approved ipilimumab, an antibody that blocks

\footnotetext{
* Correspondence: qtrinh@bwh.harvard.edu; trinh.qd@gmail.com 'Division of Urological Surgery and Center for Surgery and Public Health, Brigham and Women's Hospital, Harvard Medical School, Boston, MA, USA Full list of author information is available at the end of the article
}

the inhibitory receptor CTLA-4 expressed on T cells, (the first immunotherapeutic drug in the class of immune checkpoint inhibitors) for the treatment of advanced stage melanoma [5]. Antibodies directed against another inhibitory receptor, programmed death 1 (PD-1) and PD-1 ligand either used as monotherapy or in combination with ipilimumab have demonstrated overall survival benefit compared to ipilimumab alone and chemotherapy and are now approved by regulatory agencies and standard of care for the treatment of a number of solid and hematologic malignancies including melanoma [3, 4].

While retrospective studies have confirmed the survival benefit with immune checkpoint inhibitors in the treatment of metastatic melanoma observed in

(c) The Author(s). 2019 Open Access This article is distributed under the terms of the Creative Commons Attribution 4.0 International License (http://creativecommons.org/licenses/by/4.0/), which permits unrestricted use, distribution, and 
prospective studies, [6] there are scarce data on the adoption of immunotherapy in the community. We therefore aimed to investigate the use of immunotherapy for metastatic melanoma across hospitals over time, and sought to identify factors associated with the receipt of immunotherapy in the community. We hypothesized that certain hospitals are better equipped than others to adopt these new therapies.

\section{Material and methods}

\section{Data source}

We queried the National Cancer Database (NCDB) to obtain data from patients seen at one of 1500 Commission on Cancer $(\mathrm{CoC})$ accredited hospitals. The registry was established by the American Cancer Society and captures approximately half of melanoma cancer cases in the United States [7]. It contains sociodemographic and clinical data, including cancer characteristics and treatment information collected from trained data abstractors following standardized methodology.

\section{Study population}

Individuals diagnosed with metastatic melanoma between 2011 and 2015 were identified according to World Health Organization ICD-O3 morphological codes for malignant melanoma as well as skin topographical codes (i.e., C44.0-44.9) as previously described [6]. Metastatic stage was defined according to the collaborative stage data collection system variables indicating metastatic disease and site at diagnosis as well as clinical or pathological metastatic stage according to the American Joint Committee on Cancer, 7th Edition. If information on lactate dehydrogenase (LDH) level was available and LDH was elevated, patients were categorized as metastatic stage IVM1c. In patients with no information on LDH level metastatic stage was categorized based on metastatic site only. Patients with conflicting information about metastatic status were excluded. We only included patients who were treated at $\mathrm{CoC}$ accredited facilities that were registered throughout the study period between 2011 and 2015. Furthermore, we excluded patients with a history of a non-melanoma cancer, and patients with missing information on immunotherapy. For confidentiality reasons, we excluded patients $<20$ years of age and who were treated at facilities that treated less than 10 patients for metastatic melanoma between 2011 and 2015 (Fig. 1). In the NCDB, immunotherapy is recorded in a single treatment variable, however, since PD-1 inhibitors for advanced melanoma were approved by the FDA in late 2014, we assume that cases reporting the receipt of immunotherapy in those years were most likely ipilimumab monotherapy.

\section{Variables of interest - covariates}

Patient level information included gender, age at diagnosis, race (white, black, other, unknown), year of diagnosis, health related and cancer related characteristics comprised by the Charlson Deyo Index (CCI; categorized into $0,1,2, \geq 3$ ), primary site of the tumor (head

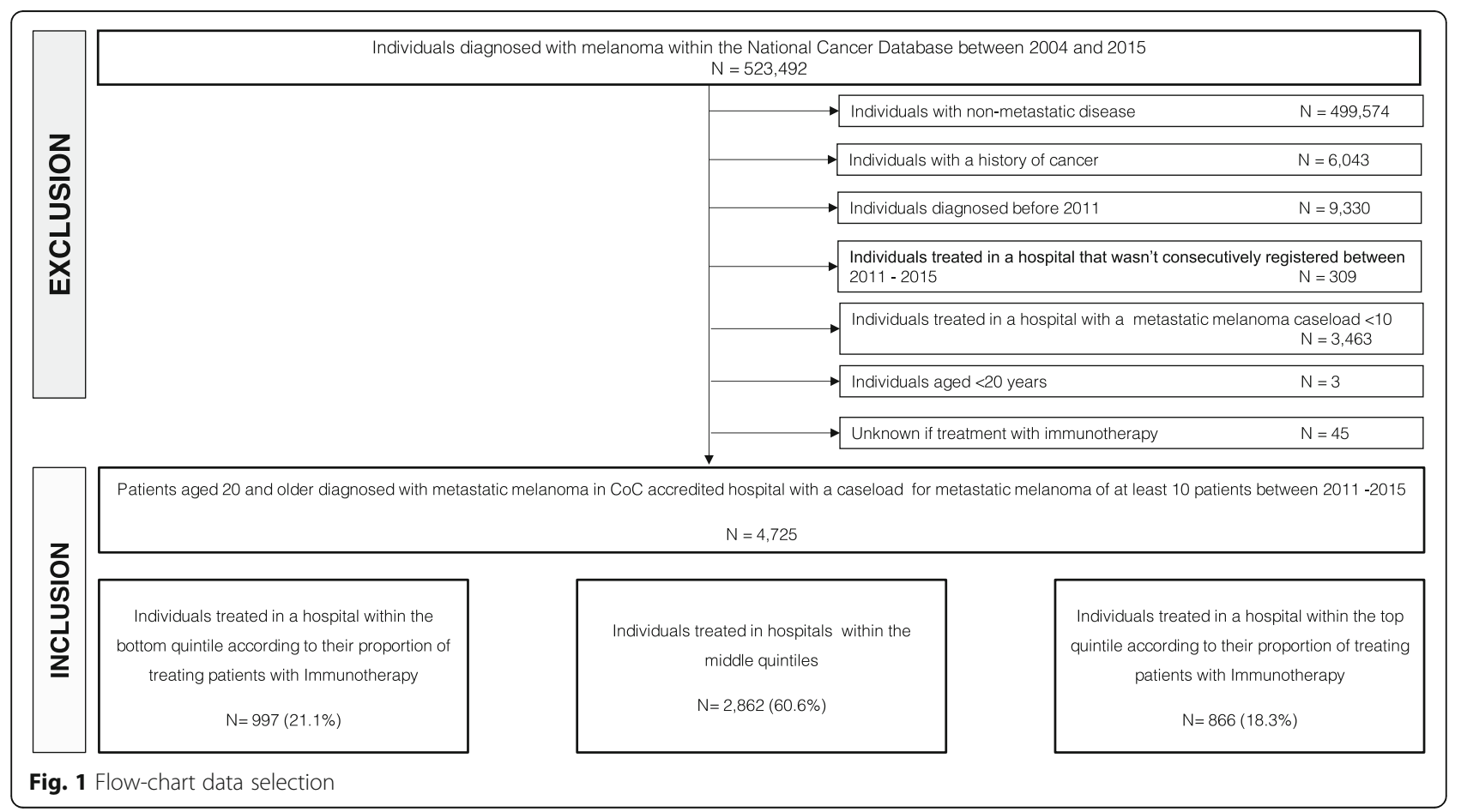


and neck, trunk, extremities, overlapping/unknown), histology (melanoma/not otherwise specified [NOS], nodular, lentigo, superficial, other/unknown), $\mathrm{M}$ stage including metastatic site (pM1/NOS, pM1a-c, brain involvement), Breslow depth and ulceration status (present, absent, unknown). Sociodemographic information contained primary insurance carrier (private, Medicaid, Medicare, other government payer [TRICARE, Military, VA and Indian/Public Health Service], uninsured, unknown), percentage of adults within patient's ZIP code without a high school diploma $(<7 \%, 7-12.9 \%$, $13-20.9 \%$, $\geq 21 \%$ ), ZIP code level median household income per year $(<\$ 38,000, \$ 38,000-\$ 47,999, \quad \$ 48$, $000-\$ 62,999$, or $\geq \$ 63,000$ ), and distance to the CoC facility. Facility level data included county type defined as an area-based measure of rurality and urban influence, using the typology published by the USDA Economic Research Service [8] (metropolitan, urban, rural, or unknown), census geographical region, and facility type categorized as Academic Program, Community Cancer Program, Comprehensive Community Cancer Program, Integrated Network Cancer Program, or other/unknown.

\section{Main outcome measure}

The main outcome measure was the rate of use of immunotherapy in hospitals treating patients with metastatic melanoma. Therefore, all hospitals were ranked according to their proportion of patients treated with immunotherapy relative to their total metastatic melanoma caseload between 2011 and 2015. Similar to an established method of stratifying volumes, $[9,10]$ we divided hospitals into quintiles. The primary comparison of interest was between hospitals in the bottom and top quintiles, defined as low and high prescribing hospitals, respectively.

\section{Statistical analysis}

First, in order to explore and describe the use of immunotherapy across hospitals over time, where time is defined as time since diagnosis, we looked at the proportion of hospitals treating at least $20 \%$ of patients with immunotherapy within 15 to 90 days from diagnosis in different diagnosis years, similar to work done by Keating et al. ${ }^{19}$. We based our threshold on the mean proportion of patients being treated with immunotherapy per hospital and year (20.6\%) which thus represents the routine use across hospitals. To account for variation in facility caseloads over time, we determined the annual caseloads of metastatic melanoma, defined as the total volume of patients with metastatic melanoma treated at the treating facility in the year of the patient's diagnosis $[11,12]$.

Second, baseline characteristics of patients treated at low vs. high prescribing hospitals were reported using medians and interquartile ranges (IQR) for continuous variables; categorical variables were presented using frequencies and proportions. Mann-Whitney $U$ test and Pearson's $\mathrm{X} 2$ test were used to compare differences in continuous and categorical variables, respectively. $\mathrm{Pa}$ tients, who were treated in hospitals of the middle quintiles were excluded from baseline analyses.

Finally, to assess possible factors associated with the receipt of treatment in a low vs. high immunotherapy prescribing hospital, we fit a multinomial logistic regression, accounting for patients who were treated in hospitals of the middle quintiles, and setting high prescribing hospital as our reference group. To account for unmeasured differences between hospitals, all regression analyses were adjusted for facility-level clustering [13].

All statistical analyses were performed using Stata v.13.0 (StataCorp, College Station, TX, USA). Two-sided statistical significance was defined as $p<0.05$. Before conducting the study, we obtained a review board waiver from our institution.

\section{Results \\ Use of immunotherapy over time}

Figure 2 depicts the use of immunotherapy across hospitals over time, stratified by diagnosis year. Of all hospitals that cared for patients with metastatic melanoma diagnosed in 2011, 0.7\% used immunotherapy in at least $20 \%$ of all patients within 15 days from diagnosis increasing to $14.5 \%$ within 90 days from diagnosis. The slope was significantly steeper in later years, with the proportion of hospitals treating at least $20 \%$ of patients within 15 and 90 days increasing from 2.8 to $37.7 \%$, respectively, in 2015.

\section{Variation in the use of immunotherapy across hospitals}

We identified 246 unique hospitals treating at least 10 patients diagnosed with metastatic melanoma between 2011 and 2015. The overall proportion of patients treated with immunotherapy was $23.8 \%$, ranging from 0 to $75 \%$ across hospitals. The mean proportion of patients receiving immunotherapy was 7.8\% (95\% Confidence Interval [CI] 7.47-8.08) and 50.9\% (95\% CI 47.6$54.3)$ at low and high prescribing hospitals, respectively (Fig. 3).

\section{Baseline characteristics of individuals treated at low vs. high prescribing hospitals}

A total of 4725 patients met inclusion criteria, 997 (21.1\%) of which were treated in low prescribing hospitals, and $866(18.3 \%)$ in high prescribing hospitals. Baseline characteristics of patients treated at low vs. high prescribing hospitals are summarized in Table 1. Patients treated at low prescribing hospitals were older (81-90 years: $16.8 \%$ vs. $8.6 \%, p<0.001$ ), sicker (CCI of 1 : 


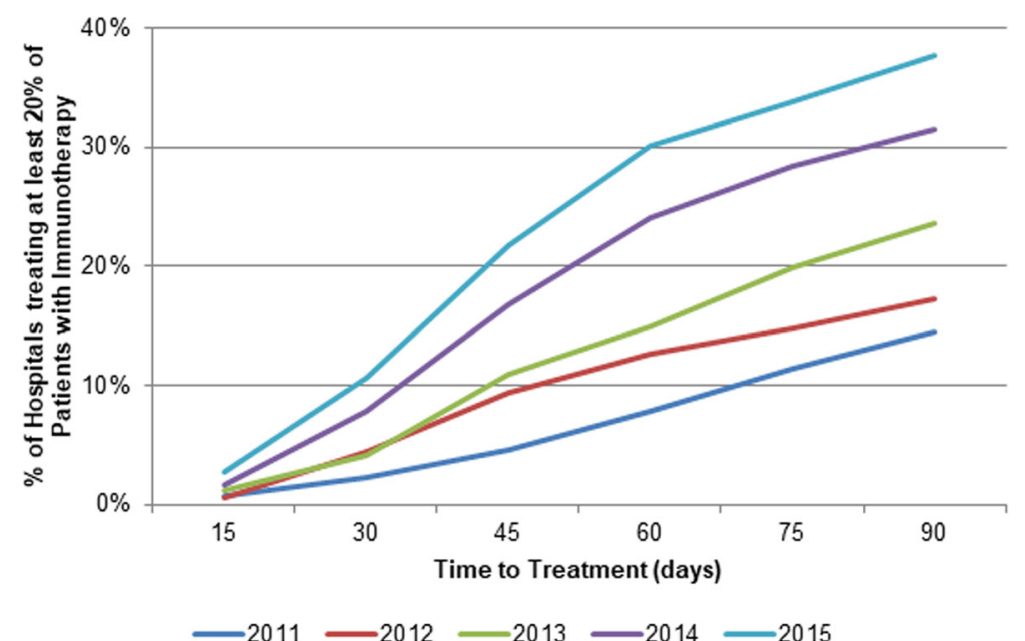

Fig. 2 Proportion of hospitals treating at least 20\% of Patients with Immunotherapy within 15 to 90 days stratified by year of diagnosis (2011-2015)

$18.4 \%$ vs. $12.7 \%, \mathrm{p}<0.001$ ), poorer (Median county-level income $\geq \$ 63,000$ : $32 \%$ vs. $45.6 \%, p=0.021)$, less educated (residence in an area where $<7 \%$ have no high school diploma: $22.4 \%$ vs. $36.8 \%, \mathrm{p}<0.001$ ), and more often had no insurance $(7.5 \%$ vs. $3.0 \%, \mathrm{p}<0.001)$. Low prescribing hospitals less often were academic centers (34.4\% vs. $82.6 \%, \mathrm{p}<0.001)$.

\section{Factors associated with receipt of treatment at low vs. high immunotherapy prescribing hospitals}

Table 2 shows predictors of receiving care in a low prescribing hospital including Medicaid insurance (relative risk ratio [RRR] 2.10, 95\% CI 1.12-3.92, $p=0.020$ ) or no insurance (RRR 2.44, 95\% CI 1.28-4.67, $p=0.007$ ) relative to private insurance, and absence of visceral metastases (RRR 0.22, 95\% CI 0.08-0.62, $p=0.004$ ). Also, patients with a long travel distance were less likely to be treated at low prescribing hospitals ( $\geq 50 \mathrm{mi}$ : RRR 0.14 , 95\% CI $0.07-0.3, \mathrm{p}<0.001)$. On a facility level, low prescribing hospitals were more likely to be a Comprehensive Community Cancer Program (RRR 5.18, 95\%CI $1.69-15.88, \mathrm{p}=0.004)$ relative to academic facilities and more likely to be located in urban areas (RRR 2.58, 95\% CI 1.34-4.96, $p=0.005)$ relative to metropolitan areas.

\section{Discussion}

We herein demonstrate not only how the use of immunotherapy for metastatic melanoma has spread over

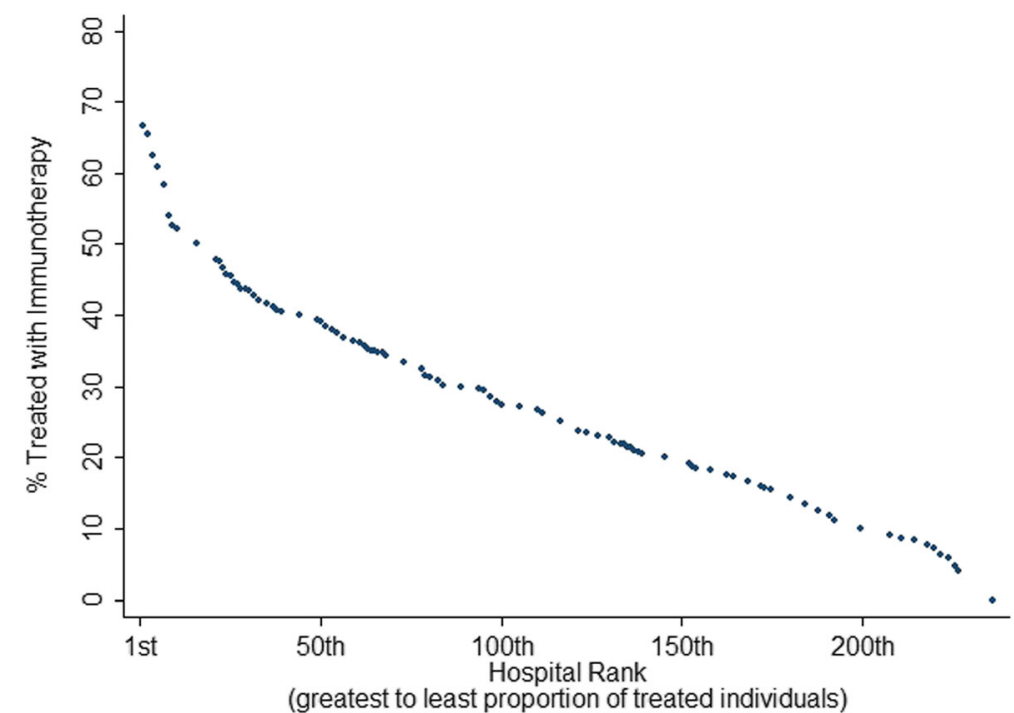

Fig. 3 Facilities $(n=246)$ ranked according to their proportion of treating patients diagnosed with metastatic melanoma with immunotherapy between 2011 and 2015 
Table 1 Baseline Characteristics of Patients with metastatic melanoma treated in low vs. high immunotherapy prescribing hospitals between 2011 and 2015

\begin{tabular}{|c|c|c|c|}
\hline & $\begin{array}{l}\text { Low prescribing Hospital } \\
N=997(53.5 \%)\end{array}$ & $\begin{array}{l}\text { High prescribing Hospital } \\
N=866(46.5 \%)\end{array}$ & $p$-value \\
\hline Age, n (\%) & & & $<0.001$ \\
\hline$\leq 30$ & $19(1.9)$ & $21(2.4)$ & \\
\hline $31-40$ & $41(4.1)$ & $66(7.6)$ & \\
\hline $41-50$ & $98(9.8)$ & $105(12.1)$ & \\
\hline $51-60$ & $181(18.2)$ & $211(24.4)$ & \\
\hline $61-70$ & $286(28.7)$ & $240(27.7)$ & \\
\hline $71-80$ & $205(20.6)$ & $149(17.2)$ & \\
\hline $81-90$ & $167(16.8)$ & $74(8.6)$ & \\
\hline Gender, n (\%) & & & 0.430 \\
\hline Female & $300(30.1)$ & $277(32.0)$ & \\
\hline Male & $697(69.9)$ & $589(68.0)$ & \\
\hline Race, n (\%) & & & 0.743 \\
\hline White & $963(96.6)$ & $832(96.1)$ & \\
\hline Black & $13(1.3)$ & $15(1.7)$ & \\
\hline Other & $21(2.1)$ & $19(2.2)$ & \\
\hline Year of Diagnosis, n (\%) & & & 0.481 \\
\hline 2011 & $188(18.9)$ & $176(20.3)$ & \\
\hline 2012 & $186(18.7)$ & $164(18.9)$ & \\
\hline 2013 & $186(18.7)$ & $182(21.0)$ & \\
\hline 2014 & $213(21.4)$ & $175(20.2)$ & \\
\hline 2015 & $224(22.5)$ & $169(19.5)$ & \\
\hline Charlson Deyo Index, n (\%) & & & $<0.001$ \\
\hline 0 & $740(74.2)$ & $723(83.5)$ & \\
\hline 1 & $183(18.4)$ & $110(12.7)$ & \\
\hline 2 & $50(5.0)$ & $24(2.7)$ & \\
\hline$\geq 3$ & $24(2.4)$ & $9(1.0)$ & \\
\hline Primary Site, n (\%) & & & 0.337 \\
\hline Head and Neck & $81(8.1)$ & $96(11.1)$ & \\
\hline Trunk & $146(14.6)$ & $119(13.7)$ & \\
\hline Extremities & $120(12.0)$ & $108(12.5)$ & \\
\hline overlapping & $650(65.2)$ & $543(62.7)$ & \\
\hline Histology, n (\%) & & & 0.035 \\
\hline Melanoma, NOS & $874(87.6)$ & $701(81.0)$ & \\
\hline Nodular & $49(4.9)$ & $76(8.8)$ & \\
\hline Lentigo & $5(0.5)$ & $14(1.6)$ & \\
\hline Superficial spreading & $25(2.5)$ & $33(3.8)$ & \\
\hline Acral lentiginous & $2(0.2)$ & $9(1.0)$ & \\
\hline other & $42(4.2)$ & $33(3.8)$ & \\
\hline Metastatic stage, n (\%) & & & 0.020 \\
\hline $\mathrm{M1}, \mathrm{NOS}$ & $89(8.9)$ & $41(4.7)$ & \\
\hline M1a & $136(13.6)$ & $110(12.7)$ & \\
\hline M1b, lung & $160(16.1)$ & $105(12.1)$ & \\
\hline M1c, visceral & $463(46.4)$ & $530(61.2)$ & \\
\hline Brain involvement & $149(14.9)$ & $80(9.2)$ & \\
\hline Ulceration, n (\%) & & & 0.333 \\
\hline
\end{tabular}


Table 1 Baseline Characteristics of Patients with metastatic melanoma treated in low vs. high immunotherapy prescribing hospitals between 2011 and 2015 (Continued)

\begin{tabular}{|c|c|c|c|}
\hline & $\begin{array}{l}\text { Low prescribing Hospital } \\
N=997(53.5 \%)\end{array}$ & $\begin{array}{l}\text { High prescribing Hospital } \\
N=866(46.5 \%)\end{array}$ & $p$-value \\
\hline No ulceration & $199(20.0)$ & $193(22.3)$ & \\
\hline Ulceration present & $135(13.5)$ & $135(15.6)$ & \\
\hline unknown & $663(66.5)$ & $538(62.1)$ & \\
\hline Breslow depth (continuous) & & & 0.559 \\
\hline Insurance, n (\%) & & & $<0.001$ \\
\hline Private & $318(31.9)$ & $415(47.9)$ & \\
\hline Medicare & $476(47.7)$ & $315(36.4)$ & \\
\hline Medicaid & $102(0.2)$ & $55(6.4)$ & \\
\hline Other Government & $18(1.8)$ & $10(1.2)$ & \\
\hline No insurance & $75(7.5)$ & $26(3.0)$ & \\
\hline unknown & $8(0.8)$ & $45(5.2)$ & \\
\hline Income* , n (\%) & & & 0.021 \\
\hline$\geq \$ 63,000+$ & $319(32.0)$ & $395(45.6)$ & \\
\hline$\$ 48,000-62,999$ & $278(27.9)$ & $238(27.5)$ & \\
\hline$\$ 38,000-47,999$ & $248(24.9)$ & $164(18.9)$ & \\
\hline$<\$ 37,000$ & $147(14.7)$ & $68(7.9)$ & \\
\hline unknown & $5(0.5)$ & $1(0.1)$ & \\
\hline Education ${ }^{* * * *}, \mathrm{n}(\%)$ & & & $<0.001$ \\
\hline$\geq 21 \%$ & $174(17.5)$ & $84(9.7)$ & \\
\hline $13-20.9 \%$ & $250(25.1)$ & $172(19.9)$ & \\
\hline $7-12.9 \%$ & $347(34.8)$ & $290(33.5)$ & \\
\hline$<7 \%$ & $223(22.4)$ & $319(36.8)$ & \\
\hline unknown & $3(0.3)$ & $1(0.1)$ & \\
\hline Great Circle Distance, n (\%) & & & $<0.001$ \\
\hline$<12.5 \mathrm{mi}$ & $531(53.3)$ & $268(31.0)$ & \\
\hline $12.5-49.9 \mathrm{mi}$ & $352(35.1)$ & $347(40.1)$ & \\
\hline$\geq 50 \mathrm{mi}$ & $112(11.2)$ & $250(28.9)$ & \\
\hline unknown & $2(0.2)$ & $1(0.1)$ & \\
\hline Facility Location, n (\%) & & & 0.017 \\
\hline Northeast & $121(12.1)$ & $289(33.4)$ & \\
\hline South & $509(51.1)$ & $171(19.8)$ & \\
\hline Midwest & $90(9.0)$ & $129(14.9)$ & \\
\hline West & $222(22.3)$ & $199(23.0)$ & \\
\hline unknown & $55(5.5)$ & $78(9.0)$ & \\
\hline Facility Type, n (\%) & & & $<0.001$ \\
\hline Academic & $324(34.4)$ & $651(82.6)$ & \\
\hline СCCP & $472(50.1)$ & $113(14.3)$ & \\
\hline INCP & $146(15.5)$ & $24(3.1)$ & \\
\hline County, n (\%) & & & 0.637 \\
\hline Metro & $838(84.1)$ & $753(87.0)$ & \\
\hline Urban & $116(11.6)$ & $89(9.9)$ & \\
\hline Rural & $18(1.8)$ & $8(0.9)$ & \\
\hline unknown & $25(2.5)$ & $19(2.2)$ & \\
\hline
\end{tabular}

Abbreviations: $\mathrm{NOS}=$ not otherwise specified, $\mathrm{mi}=$ miles; $\mathrm{CCCP}=$ comprehensive community cancer program; INCP = integrated network cancer program Significant $p$-values in italic

*ZIP-code level variable

**Percentage of residents in home county with no high school degree from 2012 American County Survey Data 
Table 2 Multinomial logistic regression predicting treatment in a low vs. high immunotherapy prescribing hospital (accounting for the middle quintiles)

\begin{tabular}{|c|c|c|c|}
\hline & Relative risk ratio & 95\% Confidence Interval & $p$-value \\
\hline \multicolumn{4}{|l|}{ Age } \\
\hline$\leq 30$ & Ref. & & \\
\hline $41-50$ & 1.04 & $0.20-5.32$ & 0.964 \\
\hline $51-60$ & 0.84 & $0.17-4.18$ & 0.834 \\
\hline $61-70$ & 1.28 & $0.25-6.49$ & 0.766 \\
\hline $71-80$ & 1.19 & $0.25-5.68$ & 0.831 \\
\hline $81-90$ & 2.24 & $0.46-10.9$ & 0.318 \\
\hline \multicolumn{4}{|l|}{ Gender } \\
\hline male & Ref. & & \\
\hline female & 0.86 & $0.62-1.18$ & 0.346 \\
\hline \multicolumn{4}{|l|}{ Race } \\
\hline White & Ref. & & \\
\hline Black & 0.36 & $0.11-1.14$ & 0.081 \\
\hline Other/unknown & 1.97 & $0.71-5.46$ & 0.193 \\
\hline \multicolumn{4}{|l|}{ Year of Diagnosis } \\
\hline 2011 & Ref. & & \\
\hline 2012 & 1.28 & $0.82-2.01$ & 0.287 \\
\hline 2013 & 1.08 & $0.69-1.70$ & 0.728 \\
\hline 2014 & 1.40 & $0.89-2.22$ & 0.147 \\
\hline 2015 & 1.83 & $1.17-2.87$ & 0.008 \\
\hline \multicolumn{4}{|l|}{ Charlson Deyo Index } \\
\hline 0 & Ref. & & \\
\hline 1 & 1.11 & $0.73-1.71$ & 0.623 \\
\hline 2 & 1.30 & $0.50-2.21$ & 0.888 \\
\hline$>=3$ & 1.93 & $0.77-4.87$ & 0.162 \\
\hline \multicolumn{4}{|l|}{ Primary Site } \\
\hline Head and Neck & Ref. & & \\
\hline trunk & 1.41 & $0.74-2.71$ & 0.294 \\
\hline extremities & 1.30 & $0.72-2.33$ & 0.379 \\
\hline overlapping & 1.25 & $0.60-2.63$ & 0.550 \\
\hline \multicolumn{4}{|l|}{ Histology } \\
\hline Melanoma, NOS & Ref. & & \\
\hline nodular & 0.78 & $0.44-1.39$ & 0.396 \\
\hline Lentigo & 0.35 & $0.04-3.44$ & 0.369 \\
\hline superficial & 0.87 & $0.38-2.00$ & 0.749 \\
\hline Acral & 0.47 & $0.07-3.01$ & 0.424 \\
\hline other & 0.91 & $0.43-1.93$ & 0.798 \\
\hline \multicolumn{4}{|l|}{ Metastatic stage } \\
\hline M1, NOS & Ref. & & \\
\hline M1a & 0.42 & $0.15-1.17$ & 0.097 \\
\hline M1b, lung & 0.39 & $0.14-1.10$ & 0.075 \\
\hline M1c, visceral & 0.22 & $0.08-0.62$ & 0.004 \\
\hline Brain involvement & 0.44 & $0.15-1.23$ & 0.116 \\
\hline \multicolumn{4}{|l|}{ Ulceration } \\
\hline No ulceration & Ref. & & \\
\hline
\end{tabular}


Table 2 Multinomial logistic regression predicting treatment in a low vs. high immunotherapy prescribing hospital (accounting for the middle quintiles) (Continued)

\begin{tabular}{|c|c|c|c|}
\hline & Relative risk ratio & 95\% Confidence Interval & $p$-value \\
\hline ulceration & 0.88 & $0.54-1.46$ & 0.631 \\
\hline unknown & 0.63 & $0.35-1.15$ & 0.132 \\
\hline Breslow (continuous) & 1.00 & $1.00-1.00$ & 0.141 \\
\hline \multicolumn{4}{|l|}{ Insurance } \\
\hline Private & Ref. & & \\
\hline Medicare & 1.13 & $0.74-1.71$ & 0.576 \\
\hline Medicaid & 2.10 & $1.12-3.92$ & 0.020 \\
\hline Other & 1.11 & $0.34-3.63$ & 0.850 \\
\hline No insurance & 2.44 & $1.28-4.67$ & 0.007 \\
\hline unknown & 0.28 & $0.07-1.16$ & 0.080 \\
\hline \multicolumn{4}{|l|}{ Income* } \\
\hline$\geq \$ 63,000$ & Ref. & & \\
\hline$\$ 48,999-\$ 62,999$ & 1.25 & $0.65-2.40$ & 0.509 \\
\hline$\$ 38,000-\$ 47,999$ & 0.93 & $0.36-2.41$ & 0.887 \\
\hline$<\$ 38,000$ & 1.71 & $0.57-5.14$ & 0.339 \\
\hline unknown & 0.29 & $0.02-3.54$ & 0.333 \\
\hline \multicolumn{4}{|l|}{ Education*:** } \\
\hline$\geq 21 \%$ & Ref. & & \\
\hline $13 \%-20,9 \%$ & 1.14 & $0.55-2.37$ & 0.730 \\
\hline $7-12,9 \%$ & 0.97 & $0.40-2.33$ & 0.943 \\
\hline$<7 \%$ & 0.61 & $0.21-1.76$ & 0.360 \\
\hline unknown & 6.10 & $0.38-98.55$ & 0.203 \\
\hline \multicolumn{4}{|l|}{ Distance } \\
\hline$<12.5 \mathrm{mi}$ & Ref. & & \\
\hline $12.5-50 \mathrm{mi}$ & 0.58 & $0.38-0.88$ & 0.011 \\
\hline$\geq 50 \mathrm{mi}$ & 0.14 & $0.07-0.30$ & $<0.001$ \\
\hline unknown & 0.38 & $0.07-2.23$ & 0.285 \\
\hline \multicolumn{4}{|l|}{ Facility Location } \\
\hline Northeast & Ref. & & \\
\hline South & 5.06 & $0.98-26.03$ & 0.052 \\
\hline Midwest & 0.97 & $0.15-6.06$ & 0.973 \\
\hline West & 1.81 & $0.35-9.30$ & 0.475 \\
\hline \multicolumn{4}{|l|}{ Facilitytype } \\
\hline Academic & Ref. & & \\
\hline CCCP & 5.18 & $1.69-15.88$ & 0.004 \\
\hline INCP & 6.60 & $1.06-41.14$ & 0.043 \\
\hline \multicolumn{4}{|l|}{ County } \\
\hline Metro & Ref. & & \\
\hline Urban & 2.58 & $1.34-4.96$ & 0.005 \\
\hline Rural & 1.93 & $0.32-11.74$ & 0.476 \\
\hline unknown & 1.25 & $0.45-3.45$ & 0.671 \\
\hline
\end{tabular}

Abbreviations: $\mathrm{NOS}=$ not otherwise specified, $\mathrm{mi}=$ miles; $\mathrm{CCCP}=$ comprehensive community cancer program; INCP = integrated network cancer program

Significant $p$-values in italic

*ZIP-code level variable

**Percentage of residents in home county with no high school degree from 2012 American County Survey Data 
time but also how its implementation has varied across hospitals and what factors predict treatment at hospitals with low vs. high use of immunotherapy. Since the approval of ipilimumab as the first immunotherapeutic drug of its kind in 2011, immunotherapy has rapidly evolved and now represents first or second-line therapy for a variety of cancers $[14,15]$. However, as demonstrated by our finding of significant facility-level variation in immunotherapy uptake, it is conceivable that the enormous economic burden of this new therapy [16] is hampering comprehensive implementation across hospitals.

When considering the general use of immunotherapy from the time of its first approval in 2011 to recent years, we found a gradual uptake in the use of immunotherapy across hospitals (Fig. 3) that is consistent with adoption curves witnessed with other novel drugs or devices [17]. The proportion of hospitals treating at least $20 \%$ of their patients with immunotherapy for metastatic melanoma within 90 days of diagnosis was approximately 2.5 times higher in 2015 compared to 2011. This trend is likely to continue as familiarity with targeted therapies increases among healthcare professionals [18].

Despite level-one evidence demonstrating a survival benefit associated with the use of immunotherapy in the treatment of metastatic melanoma, we noted significant facility-level variation in immunotherapy uptake [5]. Facility-level rates of immunotherapy use in highprescribing hospitals approached $50 \%$, compared to just $8 \%$ among low prescribing hospitals. Our results corroborate results from investigations regarding variations in the use of new therapeutics in other cancers [19]. Collectively, these results suggest that non-clinical predictors of care such as facility type may be contributing to care inequity that disproportionately affects underserved communities. Non-adherence to clinical guidelines and recommendations is a phenomenon that has repeatedly been shown across a variety of specialties and conditions (including melanoma), [20,21] which in turn may affect clinical prognosis [22, 23]. Consequently, it is critical that providers and policymakers alike identify and eliminate drivers of healthcare that is either not indicated or inadequate.

Patient and physician-level factors must also be considered as a source of the variation observed in our study [20]. A lack of experience and poor access to information regarding the appropriate use of immunotherapy may discourage physician uptake, particularly given that immune-related toxicities can result in mortality and their management often requires specific expertise [24]. From the patient's perspective, compliance with these novel drugs, especially in the context of adverse effects, requires adequate financial stability, as well as family/social support. Similarly, low prescribing hospitals were more likely to be non-academic centers that may not have early access to immunotherapy in the context of clinical trials which precede FDA approval and wider access to new agents. More than $80 \%$ of hospitals treating the highest proportion of patients with immunotherapy were academic. These academic institutions have greater access to clinical trials that may provide immunotherapy before FDA approval. Access to drugs in a clinical trial setting is likely to facilitate rapid implementation and routine use of new drugs after FDA approval because physicians will have greater familiarity with managing immune-related toxicities.

Financial aspects potentially affecting the care setting for metastatic melanoma patients must also be considered as evident by our finding that underinsured patients with Medicaid insurance or no insurance had a much higher probability of being treated in a low prescribing hospital. While drug coverage (as provided by Medicaid) is one aspect of the question, there are other factors around the treatment of the patient including payments to providers and hospitals that will be impacted by patient insurance. While most providers and hospitals - at least deliberately do not select patients according to their insurance for the simple goal of maximizing profit, there is certainly a larger scale systemic incentive to do so. Our findings are consistent with prior work showing that underserved populations experience lower quality care across a variety of health care settings $[25,26]$. The cost-intensive nature of immunotherapy is likely to exacerbate already observed health inequities experienced by the socioeconomically disadvantaged as hospitals and patients with lower means to pay for adequate treatment and lack of resources may affect treatment uptake and adherence [27]. Indeed, the administration of novel immunotherapy requires supplemental resources; in addition to the costs for the drug itself, there are added expenditures related to implementing support and pharmacy teams are required to correctly treat patients that are more easily borne by large academic centers.

Interestingly, the only clinical factor associated with lower odds of being treated at a low-prescribing hospital was the presence of visceral metastatic disease. However, factors classically used to define patient eligibility to systematic treatment, such as age or comorbidities, [28] were not different between the hospitals. There is evidence that better outcomes can be achieved when patients with complex diseases receive care at more specialized hospitals, supporting the concept of centralization [29]. It is possible that care for patients with more advanced disease may be more likely to be transferred to more experienced hospitals, there is no other clinical factor explaining differences in the use of immunotherapy. 
We acknowledge that our work has some limitations. First, we are unable to adjust for intrinsic confounding given the retrospective observational nature of our study. Second, the database we used, NCDB, is a hospital-based registry that contains only information on patients treated at $\mathrm{CoC}$ accredited hospitals. Our results may therefore not be representative for patients being treated outside of these facilities. Third, the NCDB does not capture the type or dosage of immunotherapy administered and approvals of PD-1/ PD-L1 inhibitors fall in the latter time frame of our investigation. As a result, our data are more likely to reflect adoption of ipilimumab than adoption of nivolumab and pembrolizumab though we cannot distinguish use of individual immunotherapy agents. For the same reason, it is possible that some patients received experimental immunotherapy agents on clinical trials that were not FDA approved at the time of their administration. Although it is beyond the scope of our current investigation, it will be crucial to expand our next analysis to the timeframe between 2015 and 2018 to explore the broadening indications for immunotherapy. Greater familiarity with these agents with time may lead to more rapid adoption of immunotherapy in the community and increased use in non-academic centers.

\section{Conclusion}

While the use of immunotherapy for metastatic melanoma has increased over time, adoption varies widely across hospitals. Underinsured patients were more likely to receive treatment at low immunotherapy prescribing hospitals. The variation suggests inequity in access to these potentially life-saving drugs.

\section{Abbreviations}

CCI: Charlson-Deyo-Index; Cl: Confidence Interval; CoC: Comission on Cancer; CCCP: Comprehensive Community Cancer Program; FDA: Food and Drug Administration; INCP: Integrated Network Cancer Program; IQR: Interquartile Range; LDH: Lactate dehydrogenase; NCDB: National Cancer Database; NOS: Not otherwise specified; RRR: Relative risk ratio

\section{Acknowledgements}

Quoc-Dien Trinh is supported by the Brigham Research Institute Fund to Sustain Research Excellence, the Bruce A. Beal and Robert L. Beal Surgical Fellowship, the Genentech Bio-Oncology Career Development Award from the Conquer Cancer Foundation of the American Society of Clinical Oncology, a Health Services Research pilot test grant from the Defense Health Agency, the Clay Hamlin Young Investigator Award from the Prostate Cancer Foundation and an unrestricted educational grant from the Vattikuti Urology Institute. David F. Friedlander is supported by a National Institutes of Health T32 training grant.

The National Cancer Data Base (NCDB) is a joint project of the Commission on Cancer (CoC) of the American College of Surgeons and the American Cancer Society. The CoC's NCDB and the hospitals participating in the CoC NCDB are the source of de-identified data used herein; they have not verified and are not responsible for the statistical validity of the data analysis or the conclusions derived by the authors. Quoc-Dien Trinh and Marieke Johanna Krimphove had full access to all the data in the study and take responsibility for the integrity of the data and the accuracy of the data analysis.

\section{Authors' contributions}

MJK: Conceptualization, formal analysis, investigation, methodology, visualization, writing - original draft, and writing - review and editing. KHT:
Conceptualization, writing - original draft, and writing - review and editing. DFF: Conceptualization, writing - original draft, and writing - review and editing, supervision. MM: Conceptualization, formal analysis, investigation, methodology, visualization, writing - original draft, and writing - review and editing. PR: writing - review and editing. SRL: Formal analysis, methodology, supervision, writing - review and editing. KLK: Supervision, writing - review and editing. ASK: Supervision, writing - review and editing. LAK: Supervision, writing - review and editing. PAO: Conzeptualization, supervision, writing review and editing. TKC: Conzeptualization, supervision, writing - review and editing. QDT: Conceptualization, methodology, investigation, visualization, supervision, and writing - review and editing. All authors read and approved the final manuscript.

\section{Funding}

None.

\section{Availability of data and materials}

The data that support the findings of this study are available from the American College of Surgeons but restrictions apply to the availability of these data, which were used under license for the current study, and so are not publicly available.

\section{Ethics approval}

Before conducting the study, we obtained a review board waiver from our institution.

\section{Consent for publication}

Not applicable.

\section{Competing interests}

Quoc-Dien Trinh reports honoraria from Astellas, Bayer and Janssen and Intuitive Surgical. Adam S Kibel reports consulting fees from Sanofi, Dendreon, Tokai, and Profound. Toni K Choueiri reports institutional and personal research support from AstraZeneca, Alexion, Bayer, Bristol MyersSquibb/ER Squibb and sons LLC, Cerulean, Eisai, Foundation Medicine Inc., Exelixis, Ipsen, Tracon, Genentech, Roche, Roche Products Limited, F. Hoffmann-La Roche, GlaxoSmithKline, Lilly, Merck, Novartis, Peloton, Pfizer, Prometheus Labs, Corvus, Calithera, Analysis Group, Sanofi/Aventis, Takeda. Toni K. Choueiri reports honoraria from AstraZeneca, Alexion, Sanofi/Aventis, Bayer, Bristol Myers-Squibb/ER Squibb and sons LLC, Cerulean, Eisai, Foundation Medicine Inc., Exelixis, Genentech, Roche, Roche Products Limited, F. Hoffmann-La Roche, GlaxoSmithKline, Merck, Novartis, Peloton, Pfizer, EMD Serono, Prometheus Labs, Corvus, Ipsen, Up-to-Date, NCCN, Analysis Group, NCCN, Michael J. Hennessy (MJH) Associates, Inc. (Healthcare Communications Company with several brands such as OnClive, PeerView and PER), Lpath, Kidney Cancer Journal, Clinical Care Options, Platform Q, Navinata Healthcare, Harborside Press, American Society of Medical Oncology, NEJM, Lancet Oncology, Heron Therapeutics, Lilly. Toni K. Choueiri reports consulting or advisory role with AstraZeneca, Alexion, Sanofi/Aventis, Bayer, Bristol Myers-Squibb/ER Squibb and sons LLC, Cerulean, Eisai, Foundation Medicine Inc., Exelixis, Genentech, Heron Therapeutics, Roche, GlaxoSmithKline, Merck, Novartis, Peloton, Pfizer, EMD Serono, Prometheus Labs, Corvus, Lilly, Ipsen, Up-to-Date, NCCN, Analysis Group. Toni K. Choueiri reports no speaker's bureau, no leadership or employment in for-profit companies. Other present or past leadership roles of Toni K. Choueiri: Director of GU Oncology Division at Dana-Farber and past President of medical Staff at Dana-Farber, member of NCCN Kidney panel and the GU Steering Committee, past chairman of the Kidney Cancer Association Medical and Scientific Steering Committee. Additionally, Toni K. Choueiri reports no patents, royalties or other intellectual properties. He reports travel, accommodations, expenses, in relation to consulting, advisory roles, or honoraria. His medical writing and editorial assistance support may have been funded by Communications companies funded by pharmaceutical companies. Furthermore, the institution (Dana-Farber Cancer Institute) may have received additional independent funding of drug companies or/and royalties potentially involved in research around the subject matter.

Patrick A. Ott reports consulting or advisory role with Bristol-Myers Squibb, Merck, Pfizer, Novartis, Genentech, CytomX, Array, Celldex, Neon Therapeutics as well as research funding from Bristol-Myers Squibb, Merck, AstraZeneca/ Medimmune, Celldex, CytomX, Genentech, Neon Therapeutics, ARMO Biosciences. 


\section{Author details}

'Division of Urological Surgery and Center for Surgery and Public Health, Brigham and Women's Hospital, Harvard Medical School, Boston, MA, USA. ${ }^{2}$ Department of Urology, University Hospital Frankfurt, Frankfurt am Main, Germany. ${ }^{3}$ Department of Urology, Marien Hospital Herne, Ruhr-University Bochum, Herne, Germany. ${ }^{4}$ Department of General Internal Medicine and Center for Surgery and Public Health, Brigham and Women's Hospital, Harvard Medical School, Boston, MA, USA. ${ }^{5}$ Department of Medical Oncology, Dana Farber Cancer Institute, Harvard Medical School, Boston, MA, USA.

Received: 12 April 2019 Accepted: 22 October 2019

Published online: 07 November 2019

\section{References}

1. Lowe GC, Saavedra A, Reed KB, Velazquez Al, Dronca RS, Markovic SN, et al. Increasing incidence of melanoma among middle-aged adults: an epidemiologic study in Olmsted County, Minnesota Mayo Clinic Proceed 2014;89(1):52-59. PubMed PMID: 24388022. Pubmed Central PMCID: PMC4389734. Epub 2014/01/07. eng.

2. Corrie P, Hategan M, Fife K, Parkinson C. Management of melanoma. Br Med Bull 2014;111(1):149-162. PubMed PMID: 25190764. Epub 2014/09/06. eng.

3. Schadendorf D, van Akkooi ACJ, Berking C, Griewank KG, Gutzmer R, Hauschild A, et al. Melanoma. Lancet (London, England). 2018;392(10151): 971-984. PubMed PMID: 30238891. Epub 2018/09/22. eng.

4. Sharma P, Allison JP. The future of immune checkpoint therapy. Science (New York, NY). 2015;348(6230):56-61. PubMed PMID: 25838373. Epub 2015/04/04. eng.

5. Hodi FS, O'Day SJ, McDermott DF, Weber RW, Sosman JA, Haanen JB, et al. Improved survival with ipilimumab in patients with metastatic melanoma. N Engl J Med 2010;363(8):711-723. PubMed PMID: 20525992. Pubmed Central PMCID: PMC3549297. Epub 2010/06/08. eng.

6. Dobry AS, Zogg CK, Hodi FS, Smith TR, Ott PA, lorgulescu JB. Management of metastatic melanoma: improved survival in a national cohort following the approvals of checkpoint blockade immunotherapies and targeted therapies. Cancer Immunol 2018 6. PubMed PMID: 30191256. Epub 2018/09/08. eng.

7. Lerro CC, Robbins AS, Phillips JL, Stewart AK. Comparison of cases captured in the national cancer data base with those in population-based central cancer registries. Ann Surg Oncol 2013;20(6):1759-1765. PubMed PMID: 23475400. Epub 2013/03/12. eng.

8. Agriculture USDo. Rural-urban continuum codes 2013 [June 2, 2019]. Available from: https://www.ers.usda.gov/data-products/rural-urbancontinuum-codes.

9. Zettervall SL, Schermerhorn ML, Soden PA, McCallum JC, Shean KE, Deery SE, et al. The effect of surgeon and hospital volume on mortality after open and endovascular repair of abdominal aortic aneurysms. J Vasc Surg 2017; 65(3):626-634. PubMed PMID: 27988158. Pubmed Central PMCID: PMC5329005. Epub 2016/12/19. eng.

10. Davis KF, Hohmann SF, Doukky R, Levine D, Johnson T. The Impact of Hospital and Surgeon Volume on In-Hospital Mortality of Ventricular Assist Device Recipients. J Cardiac Failure. 2016 2016/03/01/;22(3):226-231.

11. Rosen JE, Hancock JG, Kim AW, Detterbeck FC, Boffa DJ. Predictors of mortality after surgical management of lung cancer in the National Cancer Database. Ann Thorac Surg 2014;98(6):1953-1960. PubMed PMID: 25443003. Epub 2014/12/03. eng.

12. Cole AP, Trinh QD. Secondary data analysis: techniques for comparing interventions and their limitations. Curr Opin Urol 2017;27(4):354-359. PubMed PMID: 28570290. Epub 2017/06/02. eng.

13. Donner A, Donald A. Analysis of data arising from a stratified design with the cluster as unit of randomization. Stat Med 1987;6(1):43-52. PubMed PMID: 3576016. Epub 1987/01/01. eng.

14. Overman MJ, McDermott R, Leach JL, Lonardi S, Lenz HJ, Morse MA, et al. Nivolumab in patients with metastatic DNA mismatch repair-deficient or microsatellite instability-high colorectal cancer (CheckMate 142): an openlabel, multicentre, phase 2 study. Lancet Oncol 2017;18(9):1182-1191. PubMed PMID: 28734759. Pubmed Central PMCID: PMC6207072. Epub 2017/07/25. eng.

15. Motzer RJ, Tannir NM, McDermott DF, Aren Frontera O, Melichar B, Choueiri TK, et al. Nivolumab plus Ipilimumab versus Sunitinib in advanced renal-cell carcinoma. N Engl J Med 2018;378(14):1277-1290. PubMed PMID: 29562145. Pubmed Central PMCID: PMC5972549. Epub 2018/03/22. eng.
16. Buja A, Sartor G, Scioni M, Vecchiato A, Bolzan M, Rebba V, et al. Estimation of direct melanoma-related costs by disease stage and by phase of diagnosis and treatment according to clinical guidelines. Acta Derm Venereol 2018;98(2):218224. PubMed PMID: 29110018. Epub 2017/11/08. eng.

17. Carlaw KR, Woo HH. Evaluation of the changing landscape of prostate cancer diagnosis and management from 2005 to 2016. Prostate International 2017;5(4):130-134. PubMed PMID: 29188198. Pubmed Central PMCID: PMC5693456. Epub 2017/12/01. eng.

18. Francke AL, Smit MC, de Veer AJ, Mistiaen P. Factors influencing the implementation of clinical guidelines for health care professionals: a systematic meta-review. BMC Med Informatics Decision Making 2008;8:38. PubMed PMID: 18789150. Pubmed Central PMCID: PMC2551591. Epub 2008/09/16. eng.

19. Keating NL, Huskamp HA, Schrag D, McWilliams JM, McNeil BJ, Landon BE, et al. Diffusion of Bevacizumab across oncology practices: an observational study. Med Care 2018;56(1):69-77. PubMed PMID: 29135615. Pubmed Central PMCID: PMC5726588. Epub 2017/11/15. eng.

20. Heins MJ, de Jong JD, Spronk I, Ho VKY, Brink M, Korevaar JC. Adherence to cancer treatment guidelines: influence of general and cancer-specific guideline characteristics. Eur J Pub Health 2017;27(4):616-620. PubMed PMID: 28013246. Epub 2016/12/26. eng.

21. Champer M, Huang Y, Hou JY, Tergas Al, Burke WM, Hillyer GC, et al. Adherence to treatment recommendations and outcomes for women with ovarian cancer at first recurrence. Gynecol Oncol 2018;148(1):19-27. PubMed PMID: 29153542. Pubmed Central PMCID: PMC5756507. Epub 2017/11/21. eng.

22. Erickson Foster J, Velasco JM, Hieken TJ. Adverse outcomes associated with noncompliance with melanoma treatment guidelines. Ann Surg Oncol 2008;15(9):2395-2402. PubMed PMID: 18600380. Epub 2008/07/05. eng.

23. Rossi CR, Vecchiato A, Mastrangelo G, Montesco MC, Russano F, Mocellin S, et al. Adherence to treatment guidelines for primary sarcomas affects patient survival: a side study of the European CONnective TIssue CAncer NETwork (CONTICANET). Ann Oncol 2013;24(6):1685-1691. PubMed PMID: 23446092. Epub 2013/03/01. eng.

24. Miranda Poma J, Ostios Garcia L, Villamayor Sanchez J, D'Errico G. What do we know about cancer immunotherapy? Long-term survival and immunerelated adverse events. Allergol Immunopathol 2018 5. PubMed PMID: 29983240. Epub 2018/07/10. eng.

25. Stokes SM, Wakeam E, Swords DS, Stringham JR, Varghese TK, Jr. Impact of insurance status on receipt of definitive surgical therapy and posttreatment outcomes in early stage lung cancer. Surgery 2018 Dec;164(6):1287-1293. PubMed PMID: 30170821. Epub 2018/09/02. eng.

26. Grant SR, Walker GV, Koshy M, Shaitelman SF, Klopp AH, Frank SJ, et al. Impact of insurance status on radiation treatment modality selection among potential candidates for prostate, breast, or gynecologic brachytherapy. Int J Radiat Oncol Biol Phys 2015;93(5):968-975. PubMed PMID: 26452570. Epub 2015/10/11. eng.

27. Sitenga JL, Aird G, Ahmed A, Walters R, Silberstein PT. Socioeconomic status and survival for patients with melanoma in the United States: an NCDB analysis. Int J Dermatol 2018;57(10):1149-1156. PubMed PMID: 29736922. Epub 2018/05/08. eng

28. Williams GR, Mackenzie A, Magnuson A, Olin R, Chapman A, Mohile S, et al. Comorbidity in older adults with cancer. J Geriatric Oncol 2016;7(4):249-257. PubMed PMID: 26725537. Pubmed Central PMCID: PMC4917479. Epub 2016/01/05. eng.

29. Begg CB, Cramer LD, Hoskins WJ, Brennan MF. Impact of hospital volume on operative mortality for major cancer surgery. JAMA. 1998;280(20):1747-51.

\section{Publisher's Note}

Springer Nature remains neutral with regard to jurisdictional claims in published maps and institutional affiliations. 